\title{
REFLEXÕES ACERCA DO ENSINO DA SOCIOLOGIA NO BRASIL: DEBATENDO AS OCN - SOCIOLOGIA E A FORMAÇÃO DOCENTE
}

\author{
Afrânio de Oliveira Silva ${ }^{1}$ \\ Colégio Pedro II \\ Rodrigo de Souza Pain ${ }^{2}$ \\ UERJ
}

\begin{abstract}
RESUMO:
O artigo tem como objetivo discutir as Orientações Curriculares Nacionais para a disciplina de Sociologia no Ensino Médio, e também apontar considerações relevantes para a formação do docente na área. Para isso, os autores desenvolvem críticas a respeito do documento, utilizando farta visão bibliográfica, e salientam pontos relevantes a serem considerados no exercício da atividade docente como resultados significativos da pesquisa.
\end{abstract}

PalaVRas-Chave: Sociologia - Ensino Médio - Formação Docente

\section{ABSTRACT:}

The objective of this article is to discuss the Brazilian National Curriculum Guidelines for the subject of Sociology at the high school level - Ensino Médio -, and to point out relevant considerations for teacher training in the area. To this end, the authors develop a critical analysis, using a wide range of resources, and highlight important points to be considered regarding the practice of teaching as significant results to this research.

KEYWORDS: Sociology - Upper school - Teacher training

\section{INTRODUÇÃO}

$\mathrm{O}$ artigo pretende discutir as Orientações Curriculares Nacionais para o Ensino Médio, para a área de Sociologia, à luz das reflexões acadêmicas e experiências da prática docente. $\mathrm{O}$ texto busca abordar, inicialmente, o complexo caminho histórico percorrido pela disciplina. A seguir, será exami- nado o desenvolvimento do pensamento sociológico e as razões para a Sociologia no Ensino Médio. Analisar os recortes, trazidos pelas OCN -Sociologia, para o trabalho docente, está no próximo ponto que segue. $\mathrm{E}$ por fim, buscar-se-á traçar alguns comentários sobre a formação dos professores de Sociologia.

Tendo como referência as diversas e 
e-Mosaicos - Revista Multidisciplinar de Ensino, Pesquisa, Extensão e Cultura do Instituto de Aplicação Fernando Rodrigues da Silveira (CAp-UERJ)

ANO 1 - V. 1 - N. 2 - DEZEMBRO 2012 - ISSN: 2316-9303

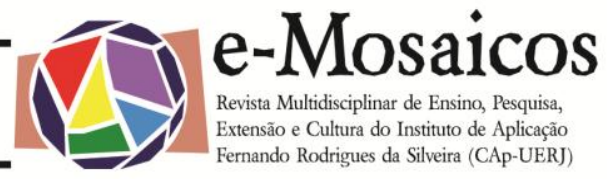

complexas realidades sociais que envolvem professores, alunos e escolas, o objetivo do presente trabalho é contribuir para o debate a respeito do papel do professor de Sociologia do Ensino Médio. Não é interesse dos autores trazer respostas prontas para as diversas inquietações sobre a prática docente. $\mathrm{O}$ que se busca é apontar fragilidades, propor caminhos, debater os desafios, e principalmente, trazer à baila a reflexão do professor que ensina (ou pretende lecionar) Sociologia no Ensino Médio.

\section{OCNS E A PRÁTICA DOCENTE}

Ao buscar trazer o debate sobre a reflexão docente para o Ensino Médio, o Ministério da Educação do Governo Lula trouxe publicações relevantes sobre as Orientações Curriculares Nacionais para o Ensino Médio (OCNs). No que diz respeito à Sociologia, o texto, inicialmente, aponta para o desenvolvimento da disciplina no âmbito da educação no país. Nesse sentido, rapidamente percebe-se que a Sociologia possui uma historicidade bem diferente das demais disciplinas, no que diz respeito ao currículo. Em determinados momentos, a disciplina foi obrigatória, como em 1942, curiosamente no governo ditatorial de Vargas. Em outros momentos, como em 1961, a Lei de Diretrizes e Bases da Educação Nacional colocou a disciplina como optativa ou facultativa. Já nos governos militares (1964-1985), a disciplina sofreu com o autoritarismo político, e ficou limitada no que diz respeito a sua legitimidade, inclusive com censura de determinados conteúdos.

Além de sua limitação - não só da Sociologia, como também das outras ciências humanas - no que diz respeito à Sociologia, o regime propiciou a elevação do status das disciplinas de Educação Moral e Cívica (EMC) e de Organização Social e Política
Brasileira (OSPB), utilizadas como instrumentos de propaganda doutrinária e ideológica da situação ${ }^{1}$ (RAIZER et alii 2007:2). Em 2009, depois de anos de debate, o Conselho Nacional de Educação regulamenta 0 modo de implementação da Filosofia e da Sociologia, nas três séries do Ensino Médio, pela Resolução número 1 , de 15 de maio de 2009 , ordenando que se conclua a efetivação dessa medida até 2011.

A partir dessa historicidade particular da disciplina, a OCN -Sociologia desenvolve a relação entre a Sociologia e a prática da Cidadania. Diferente do que traz o senso comum, não é exclusividade da disciplina o debate sobre a formação do cidadão. Muito pelo contrário, a questão de formar cidadãos críticos deve passar por todas as disciplinas, e não ser responsabilidade exclusiva da Sociologia.

Depois de chamar atenção para esse importante ponto, a OCN - Sociologia entra no papel central do pensamento sociológico. Segundo o documento, a desnaturalização e o estranhamento devem representar as linhas básicas de raciocínio no campo da disciplina. Desnaturalizar os fenômenos sociais é fundamental na reflexão sociológica, pois, atualmente, as informações chegam com mais velocidade e, dessa maneira, a falta de reflexão mais apurada tornou-se característica marcante da 'sociedade informacional', como denominou o sociólogo contemporâneo Manuel Castells (2000). Tudo parece ser tão natural e dado pela natureza, portanto nunca construído socialmente. Já o estranhamento deve ser percebido a partir da construção sociológica de cultura, e per-

\footnotetext{
${ }^{1}$ Ao entrevistar professores de outras disciplinas, percebe-se facilmente que ainda existe uma confusão no que diz respeito às diferenças entre a Sociologia, a Educação Moral e Cívica e a Organização Social e Política Brasileira, principalmente entre os docentes mais antigos.
} 
e-Mosaicos - Revista Multidisciplinar de Ensino, Pesquisa, Extensão e Cultura do Instituto de Aplicação Fernando Rodrigues da Silveira (CAp-UERJ)

ANO 1 - V. 1 - N. 2 - DEZEMBRO 2012 - ISSN: 2316-9303

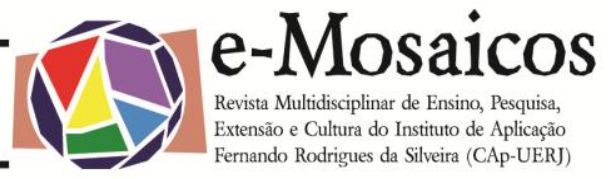

cebido no reconhecimento das diferenças. A perspectiva do relativismo cultural e toda complexidade do debate que envolve o multiculturalismo e etnocentrismo deve ser travada à luz do conhecimento sociológico. Assim, refletir a cultura a partir de uma perspectiva antropológica nos permite conviver plenamente com a pluralidade, respeitando o espaço do outro.

Apesar de apontar para as orientações, o texto traz críticas aos docentes. A transposição de conteúdos e práticas do ensino superior para o ensino médio deve ser condenada. Esse "academicismo" dos sociólogos deve ficar restrito à academia e aos debates entre os docentes. Não se pode esquecer que o objetivo não é formar sociólogos no ensino médio, e sim alunos preparados para a vida acadêmica. Como chamanos a atenção Nelson Tomazzi,

"(...) Aqueles professores que pensam em reproduzir o que aprenderam na universidade, somente causam grande problema para o desenvolvimento da disciplina no ensino médio. Estes muitas vezes reproduzem um conteúdo exclusivamente acadêmico, porque ou não possuem formação adequada para esta tarefa, ou não querem ser professores para este nível" (TOMAZZI in RABELO e SANTOS, 2009:03).

Vale lembrar que no projeto político pedagógico do tradicional Colégio Pedro II primeira instituição de ensino secundário no Brasil a introduzir o ensino da Sociologia em sua grade curricular - para a área da Sociologia faz essa importante ressalva, "(...) não se trata de recompor as disciplinas acadêmicas do ensino superior no ensino médio" (2002:351). Igualmente, chama-se atenção também para a linguagem que o professor deve ter em sala de aula no Ensino Médio. Reproduzir determinados termos, com o vício do academicismo, certamente não traz bons resultados em termos de compreensão do alunado.

Logo, o que o docente pode esperar, ao realizar seu trabalho com o aluno do Ensino Médio, é que ele conquiste, como traz Tomazzi, lembrando Charles Mills, a imaginação sociológica. Ou seja, a preocupação do professor de Sociologia é desenvolver nos seus alunos a capacidade de ver a realidade em que vivem com outro olhar, além do senso comum (TOMAZZI, 597:2007). De acordo com Charles Mills, é entender as transformações pelas quais passa a sociedade, ou "uma qualidade de espírito que Ihes ajude a usar a informação e a desenvolver a razão, a fim de perceber, com lucidez, o que está ocorrendo no mundo e o que pode estar acontecendo dentro deles mesmo" (1982:11).

Destarte, o texto da OCN, após essas ressalvas e críticas, aponta as razões para a Sociologia estar no currículo do ensino médio. Segundo o texto, a ideia de humanizar o homem deve estar presente. Afinal, tratase das Ciências Humanas, e esse princípio deve nortear todas as disciplinas. Em uma sociedade altamente competitiva e individualista como a atual, pensar no coletivo e na comunidade é fundamental. $O$ documento produzido pelo Colégio Pedro II também vai nessa direção, quando critica a "ideologia do individualismo extremado", e vai além, afirmando que "(...) não se pode dissociar, no interior da experiência social concreta, 0 binômio sociedade-indivíduo" (2002:352). Além disso, a banalização da violência proporciona a insensibilidade do sofrimento, a falta de respeito e também a invasão da liberdade do outro. Essa ideologia do individualismo busca diminuir as iniciativas coletivas e faz aumentar a segregação e a exclusão.

Mais uma razão relevante, segundo a OCN - Sociologia, está na medida em que a escola é um espaço de mediação entre o 
e-Mosaicos - Revista Multidisciplinar de Ensino, Pesquisa, Extensão e Cultura do Instituto de Aplicação Fernando Rodrigues da Silveira (CAp-UERJ)

ANO 1 - V. 1 - N. 2 - DEZEMBRO 2012 - ISSN: 2316-9303

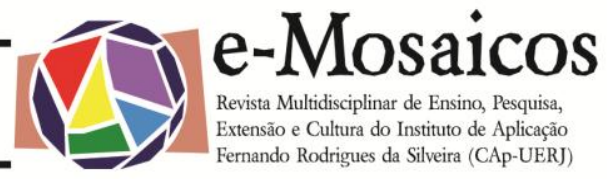

privado (a família) e o público (a sociedade) ela deve favorecer essa transição. Ou seja, a instituição escola também deve ser objeto de estudo da disciplina. O professor do Departamento de Ciências Sociais da Universidade Federal de Goiás, Revalino Freitas, concorda quando afirma que "(...) a própria escola, instituição, pode vir a ser tem de estudos sociológicos (...) numa constante revisitação de seus sentidos e objetivos (...)'. Portanto, argumenta-se que refletir sobre o próprio ambiente escolar torna-se importante como ideia de pertencimento a esse grupo social, e a busca pela melhoria da instituição faz com que o aluno se veja como um ator ativo na própria sociedade.

Por fim, a outra razão, apontada pelo texto da OCN está no seu imperativo político, ou seja, o conhecimento científico dos processos que constituem a desigualdade social. Desta forma, pensar sobre a relação entre as classes sociais é fundamental, assim como entender a dinâmica do consumismo, da indústria cultural, dos movimentos sociais dos excluídos, e de tantos elementos que estão inseridos nesse contexto. É nesse sentido que o pensador contemporâneo francês Pierre Bourdieu afirma que a Sociologia é uma ciência que incomoda porque questiona as outras ciências e é inquietante porque revela coisas escondidas, com as quais muitas vezes não nos queremos confrontar. Desta maneira, existem determinados grupos de intelectuais que não gostam das "verdades" que a Sociologia apresenta porque Ihes são bastante incômodas $^{2}$ (2002).

O documento traz outras críticas, como

\footnotetext{
${ }^{2} \mathrm{O}$ autor também aponta sobre os questionamentos do caráter científico da disciplina. Segundo Bourdieu, a Sociologia é uma ciência crítica, com conhecimentos adquiridos, conceitos, métodos de investigação e procedimentos de verificação (1984:
} 61). a redução da Sociologia aos conhecimentos de história e filosofia. Ora, a Sociologia estuda fenômenos sociais e esses não ocorrem apenas no tempo e no espaço: têm suas leis próprias, específicas das relações sociais. É nesse sentido que entendemos que a produção do conhecimento sociológico tem suas especificidades que o Ensino Médio, dentro de suas limitações, deve abraçar.

No que diz a proposta curricular, o texto aponta a fragilidade da institucionalização do currículo da disciplina. Porém, por um lado traz uma vantagem, a da liberdade de ação. Por outro, a desvantagem da falta de sequencia, ou de pré-requisito. Acredita-se que essa é uma questão importante porque está no cerne do conteúdo que se pretende aplicar aos alunos, e nas séries correspondentes. Eis uma lacuna importante que merece a atenção dos docentes da Sociologia. De acordo com o pedagogo francês Philippe Meirieu, o princípio da progressividade programática, presente nas escolas, acaba por determinar os saberes que são fundamentais aos educandos e o nível de complexidade destes na proposta curricular. Desta forma, o autor dá como exemplo a letra que vem antes da palavra, a frase antes do texto, o texto antes do livro, o livro antes do autor. Assim, diante desses pensamentos, Meirieu provoca os educadores a elaborar programas escolares com responsabilidade política, ao perguntar o que é necessário que o conjunto dos cidadãos conheça para viver em comunidade? Que conhecimentos históricos, artísticos, científicos são necessários para compartilhar?(2005: 38-39). É importante, para os docentes da Sociologia refletir sobre que tipo de proposta curricular é a mais interessante para suas escolas, levando-se sempre em consideração as particularidades sociais e culturais do seu ambiente de trabalho.

Dessa forma, o texto faz três recortes 
e-Mosaicos - Revista Multidisciplinar de Ensino, Pesquisa, Extensão e Cultura do Instituto de Aplicação Fernando Rodrigues da Silveira (CAp-UERJ)

ANO 1 - V. 1 - N. 2 - DEZEMBRO 2012 - ISSN: 2316-9303

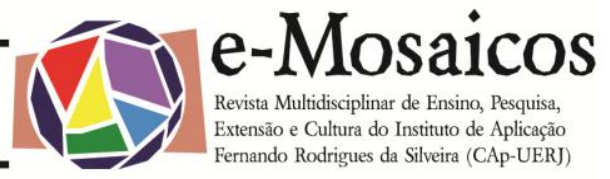

para o trabalho docente. Primeiro é trabaIhar o conceito como elemento de conhecimento racional que permite melhor explicar ou compreender a realidade. Assim, ter-seia, de acordo com o documento, a vantagem de elevar o patamar de análise do aluno com o discurso científico para além do senso comum (o que é de extrema importância para a disciplina). Porém, temos a desvantagem, pois diferentes formas de sentido podem dificultar a compreensão do aluno e a dificuldade de trazer para a realidade discente. Nesse ponto está um desafio significativo para o docente, buscar o(s) conceito(s) adequado(s). Talvez utilizar mais de um conceito sobre determinada questão pode ser importante, como também evitar radicalismos, verdades pré-concebidas e ausência da historicidade conceitual. Além disso, em entrevistas realizadas com docentes do Ensino Médio de Sociologia da rede estadual de educação, percebemos que pouquíssimos professores procuram trabaIhar mais de um conceito sobre determinado assunto em suas aulas. Isso é perigoso porque pode "fechar" outras interpretações a respeito do mesmo tema, e assim fazer com que o discente fique com uma ideia única e fechada a respeito de conceito. Além disso, como apontam os professores Amauri Moraes e Elisabeth Guimarães, o emprego de um conceito, mesmo no Ensino Médio, demanda uma série de referências: em relação à sua origem, o contexto social em que foi criado os fenômenos que exigiram a tradução das ansiedades sociais no momento de sua criação, os contextos que antecederam e condicionaram as concepções de seus criadores, as propostas definidoras do universo em que ele se constituiu e as transformações que sofreu ao longo da sua elaboração (2010:50). Por fim, percebe-se com clareza que o tempo destinado a nossa disciplina dificulta, e muito, na busca pela qualidade de nossas aulas. É visão dos autores que a carga horária da Sociologia seja revista em prol da qualidade do ensino da disciplina.

O texto também aponta para a importância de trabalhar com temas. Faz-se necessário a adequação à realidade do aluno partindo de casos concretos articulando conceitos e teorias. Como vantagem, a familiarização dos alunos com a disciplina, e com isso, permite despertar o interesse dos discentes, principalmente com os temas da atualidade. Como desvantagem, a necessidade do professor ter grande capacidade analítica e amplo conhecimento sobre a realidade social.

Por fim, o terceiro recorte que o texto traz está na teoria como modelos explicativos. Isso possibilita o aluno conhecer a história do pensamento sociológico, e mais de uma explicação para um fenômeno social. A desvantagem está na necessidade de apresentar uma síntese, e não cair no discurso reproduzido da academia. Para Morais e Guimarães, no Ensino Médio, os conteúdos teóricos devem estabelecer relação mais direta com as realidades próximas das experiências dos educandos. A sugestão dos autores é que elas sejam associadas a recursos didáticos que sejam eficientes para tratar tais temas com os discentes (2010:52). Vale recordar do pedagogo e humanista Paulo Freire que nega o que ele chama de "ensino bancário", ou seja, a simples exposição de conteúdos. O professor sabe e os alunos não sabem, assim mantendo a divisão entre os oprimidos e opressores. O educando é visto como meros depositários de uma bagagem de conhecimento que deve ser assimilada sem discussão. Para o ator é extremamente importante a valorização da interação entre o educador e o educando. Essa interação é o encontro da teoria com a prática, as quais, separadamente, não permitem a criação de novos saberes, nem a construção da cidadania. 
e-Mosaicos - Revista Multidisciplinar de Ensino, Pesquisa, Extensão e Cultura do Instituto de Aplicação Fernando Rodrigues da Silveira (CAp-UERJ)

ANO 1 - V. 1 - N. 2 - DEZEMBRO 2012 - ISSN: 2316-9303

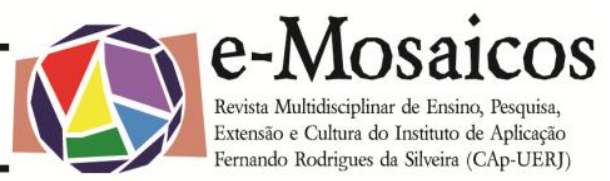

Desse modo, essa metodologia não aceita a arrogância ou o determinismo de uma relação hierárquica de aprendizagem, na qual um é o sujeito e o outro é o objeto, e aposta na interação ente o educando e o educador, em que ambos são sujeitos na construção dos saberes (1996:59).

O documento da OCN - Sociologia também aponta que a pesquisa sociológica deve estar presente nos três recortes, na teoria como verificação e problematizar os resultados. Além disso, afirma que as pesquisas são ainda bastante incipientes (Brasil, 2006:104). De acordo com Freitas, a investigação deve estar presente em sala de aula como produção do conhecimento sociológico. As aulas de Sociologia não cabem em métodos rígidos, mas sim acontecer no sentido de explorar o que mais interacional existe em termos de métodos pedagógicos. A sua característica de interação com a realidade requer perspectivas diversas (2008:07). Outro autor, o pedagogo Pedro Demo, afirma que a pesquisa adensa a instrumentação teórico - prática para o exercício da cidadania e participação do processo produtivo do conhecimento. Nesse contexto, pode-se afirmar, ainda de acordo com o autor, que o professor precisa ser um pesquisador, saber ler a realidade criticamente e fazer da pesquisa um princípio educativo, parte inerente do processo pedagógico. É no decorrer da pesquisa que professor e aluno fazem a leitura da realidade, transmitindo um olhar crítico para saber intervir de forma alternativa, com base na capacidade questionadora (1999:16). O projeto político pedagógico do Colégio Pedro II para a disciplina de Sociologia também aponta nessa direção quando afirma que, "(...) 0 aluno precisa aprender, na prática, a fazer pesquisa: coletando, selecionando, sistematizando $e$ analisando dados e informações" (2002:351). Também chama-se a atenção para a importância da pesquisa bibliográfica, no sentido de orientar sobre a natureza das fontes; além do trabalho de campo, com entrevistas, observação participante e na busca por outras metodologias apropriadas.

\section{A SOCIOLOGIA E A FORMAÇÃo dOS FUTUROS DOCENTES DA ÁREA}

A formação dos professores é extremamente importante nesse cenário apontado acima. Diversos problemas aparecem na qualificação do futuro profissional que atuará no magistério como docente em Sociologia. Percebe-se, como salienta o sociólogo e professor do Colégio de Aplicação da Universidade do Estado do Rio de Janeiro, Rogério Mendes, que docência no ensino básico e pesquisas são incompatíveis. Isso é preocupante, pois se imagina o professor do ensino médio como apenas um reprodutor do conhecimento. Segundo o escritor, apesar de oferecerem a licenciatura como habilitação a ser conquistada, os cursos de graduação não organizaram concretamente seus currículos com esse objetivo. Os cursos de Ciências Sociais são preparados para formar pesquisadores em Ciências Sociais, ou seja, bacharéis. Assim, ao optar pela educação básica, muitas vezes não há a preocupação com a formação teórica e para a pesquisa deste futuro docente. Ainda de acordo com Rogério Mendes, as universidades dão pouca atenção no desenvolvimento dos cursos de licenciatura (2009:200).

Essa abordagem torna-se importante também quando se percebe o pouco interesse dos alunos da graduação em Ciências Sociais com as cadeiras oferecidas pela Licenciatura na área. Podemos acrescentar que a desvalorização do professor no mercado de trabalho também parece contribuir nessa falta de disposição por parte do discente. Acredita-se ser fundamental que o estagiário de docência receba uma bolsa 
e-Mosaicos - Revista Multidisciplinar de Ensino, Pesquisa, Extensão e Cultura do Instituto de Aplicação Fernando Rodrigues da Silveira (CAp-UERJ)

ANO 1 - V. 1 - N. 2 - DEZEMBRO 2012 - ISSN: 2316-9303

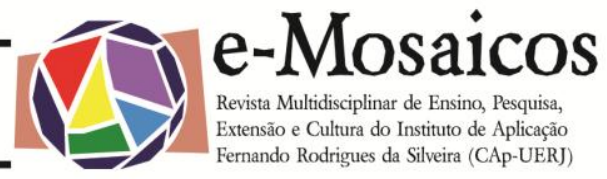

para seu estágio. Os governos não devem olhar a educação como gasto, e sim investimento. A busca pelo desenvolvimento no Brasil passa prioritariamente pela educação pública e de qualidade.

Desta maneira, o ensino de Sociologia nas escolas do ensino médio não logrou ser uma preocupação nos cursos de graduação em Ciências Sociais. De acordo com Ileizi Silva, citando levantamento feito por Amauri Moraes, evidencia esse fato demonstrando que a interrupção da Sociologia nos currículos do Ensino Médio foi acompanhada também das interrupções das reflexões no interior da comunidade das Ciências Sociais, provocando assim um mal-estar com relação à licenciatura (2010:25). Portanto, estamos vivenciando um momento extremamente importante na consolidação da Sociologia como disciplina do Ensino Médio, e as reflexões sobre os diversos aspectos que envolvem a prática docente devem ser estimuladas, inclusive pensando nas contribuições que a disciplina pode dar no Ensino Fundamental, já que temos experiências exitosas nesse sentido, principalmente com a presença da disciplina de Ciências Sociais para os alunos do Ensino Fundamental no Colégio Pedro II.

Nesta mesma instituição está sendo desenvolvido o Programa de Residência docente, uma experiência inovadora de formação de professores. 0 programa pretende formar/aperfeiçoar a prática docente de professores da rede pública de ensino do Rio de Janeiro (Municipal e Estadual). O método de ensino enfatiza a prática de sala de aula, com oficinas didático-pedagógicas e convívio diário nas salas de aula do Colégio Pedro II. Essa troca de experiência tem gerado frutos interessantes, apesar de pouco tempo de funcionamento. Os limites impostos à prática pedagógica nas instituições da rede estadual não são percebidos, em sua maioria, nas dependências do Colégio Pedro II. Infraestrutura, apoio técnico, perfil do público, reuniões de professores da área e carga horária (dois tempos) são os principais elementos de disparidade que impactam diretamente na prática pedagógica. Alinhar as perspectiva sobre realidades tão distintas é o maior desafio encontrado nesse projeto. Como fazer para não alijar o aluno da rede pública estadual de aulas realmente interessantes e aprofundadas sem contar com o básico necessário para o desenvolvimento do trabalho pelo professor? Como elaborar o planejamento com projetos políticos pedagógicos tão distintos e na maior parte das vezes apenas peças figurativas? $\mathrm{E}$ por fim, 0 momento mais rico desse processo tem sido pensar material didático, para além do livro didático, para se trabalhar em sala de aula. Neste quesito, linguagem, conteúdo, método, tamanho e densidade, tudo se apresenta como desafio para o trabalho desenvolvido tendo como foco os alunos da rede pública.

\section{CONSIDERAÇõES FINAIS}

O presente trabalho teve como objetivo debater a OCN - Sociologia levando-se em consideração aspectos relacionados à prática docente. $\mathrm{O}$ artigo não teve objetivo de esgotar as possibilidades de discussão em torno dos temas aqui tratados, nem apontar qualquer solução uniforme ou mecânica diante de tanta diversidade cultural e social que envolve uma série de atores dentro da comunidade escolar. Tão somente tivemos objetivo de trazer uma leitura crítica do documento, e também chamar atenção para as debilidades na formação de professores.

A preocupação com a qualidade da educação deve estar no cerne das políticas públicas desenvolvidas pelos governos e pelo Estado brasileiro. A disciplina de Socio- 
logia tem sua especificidade histórica nos currículos brasileiros, e recentemente, com a obrigatoriedade no Ensino Médio, tornouse fundamental a reflexão sobre a prática docente entre os professores da área. Além disso, a conquista da democracia em nosso país proporcionou o debate com as múltiplas visões de mundo e valorizou os diversos pensamentos sobre a realidade social. Nesse sentido a Sociologia tem muito que contribuir. Este artigo é também um convite para os jovens professores e pesquisadores debruçarem seus estudos nessa área. O desafio é de todos nós.

\section{REFERÊNCIAS BIBLIOGRÁFICAS:}

BOURDIEU, Pierre. La Sociologia es uma ciência?. In: La recherche, n. 331, 2000.

Sociologia y cultura. Grjalbo-Consejo Nacional para la Cultura y las Artes, México, 1984.

BRASIL. Ministério da Educação. Secretaria da Educação Básica. Ciências humanas e suas tecnologias In: Orientações curriculares para o ensino médio. Brasília, DF: MEC/SEB, 2006.

CASTELLS. Manuel. A era da informação: economia, sociedade, e cultura. In: A sociedade em rede. São Paulo: Paz e Terra, 2000.

COLÉGIO PEDRO II. Projeto Político Pedagógico. Ministério da Educação e Cultura, Brasília, 2002.

DEMO, Pedro. Pesquisa; princípio científico e educativo. 6 ed. São Paulo, Cortez, 1999.

FREIRE, Paulo. Pedagogia da autonomia; saberes necessários à prática educativa. São Paulo, Paz e Terra, 1996.

FREITAS, Ravelino Antonio e ABE, Hyra Hykeno. A Sociologia no Ensino Médio: entre o mercado de trabalho e a vida. I Simpósio Estadual sobre a formação de professores de Sociologia. Universidade Estadual de Londrina, 2008.

MENDES, Rogério. A Sociologia no ensino básico: desafios e dilemas. In HANDFAS, Anita e OLIVEIRA, Luiz Fernandes. A Sociologia vai à escola: história, ensino e docência. Rio de Janeiro, FAPERJ, 2009.

MEIRIEU, Philippe. O cotidiano da escola e da sala de aula; o fazer e o compreender. Porto Alegre, Artmed. 2002.

MILLS, C. Wright. A imaginação sociológica, Rio de Janeiro, Zahar, 1982.

MORAES, Amaury César e GUIMARÃES, Elisabeth da Fonseca. Metodologia de Ensino de Ciências Sociais: relendo as OCEM - Sociologia. Coleção explorando o Ensino. Ministério da Educação, Brasília, 2010.

RABELO, Josevânia Nunes e SANTOS, Andréa Ribeiro. $A$ "legitimação" do ensino da Sociologia na rede pública de Aracajú-SE. XI Congresso Brasileiro de Sociologia. Rio de Janeiro, 2009.

RAIZER, Leandro et Alii. $A$ importância da disciplina de Sociologia para a construção de uma escola de qualidade. In: XXII Simpósio da ANPAE; I Colóquio Ibero Americano de Política e Administração da Educação, 2007, Porto Alegre. Anais do XXIII Simpósio da ANPAE; I Colóquio Ibero Americano de Política Administração da Educação. Porto Alegre: UFRGS, 2007. V.1. p.200-201. 
SILVA, Ileizi Luciana Fiorelli. 0 ensino das Ciências Sociais / Sociologia no Brasil: histórias e perspectivas. Coleção Explorando o Ensino. Ministério da Educação, v.15, Brasília, 2002.

TOMAZZI, Nelson Dacio. Conversa sobre Orientações Curriculares Nacionais (OCNs). Revista Cronos, UFRN, v.8, n.2, Natal, jul/dez, 2007.

\footnotetext{
1 afranioliveiras@gmail.com - Professor de Sociologia do Colégio Pedro II, da Universidade do Estado do Rio de Janeiro (UERJ), Supervisor do Programa de Pós-Graduação Residência Docente do Colégio Pedro II e Doutorando em Ciências Sociais pelo CPDA/UFRRJ.

2 rodrigo.pain@gmail.com - Professor de Sociologia da SEEDUC, do Colégio de Aplicação da Universidade do Estado do Rio de Janeiro (CAp UERJ), da Universidade do Estado do Rio de Janeiro (UERJ), aluno do Programa de PósGraduação Residência Docente do Colégio Pedro II e Doutor em Ciências Sociais pelo CPDA/UFRRJ.
} 